Paula Tesche - Javier González, Violencia política contra el MIR en Concepción, región del Biobío: Cuartel Bahamondes como centro de operación, detención y tortura en 1984, Izquierdas, 48, noviembre 2019:126-142

\title{
Violencia política contra el MIR en Concepción, región del Biobío: Cuartel Bahamondes como centro de operación, detención y tortura en 1984*
}

Political violence against MIR in Concepción, Biobio region: the cuartel Bahamondes as an operation, detention and torture center in 1984.

\author{
Paula Tesche Roa** Javier González Alarcón ${ }^{* * *}$
}

\begin{abstract}
Resumen: Este artículo tiene como macro objetivo visibilizar los antecedentes históricos sobre la violencia política por parte del Estado en Concepción, que se corresponden con la operación retorno, y posterior represión durante la dictadura cívico militar $(1973$ - 1990) del Movimiento de Izquierda Revolucionario (MIR). En particular, interesa demostrar, desde el enfoque de la historia reciente, el supuesto que durante la década de los 80 , se implementaron acciones de violencia política, como la instalación del centro de detención y tortura, denominado "Cuartel Bahamondes", destinadas a aniquilar y exterminar las acciones de resistencia. La metodología comprende el análisis de fuentes primarias, archivos arzobispado de Concepción y testimonios, así como fuentes secundarias de tipo periodística y académica. Los hallazgos evidencian la necesidad de poner en valor y resignificar los relatos y los espacios de memoria locales.
\end{abstract}

Palabras clave: Violencia política de Estado, Movimiento Izquierdista Revolucionario (MIR), dictadura cívico militar en Concepción, Cuartel Bahamondes.

\begin{abstract}
The general objective of this chapter is to make visible some historical backgrounds about the political violence perpetrated by the State in Concepción, wich corresponds to the return operation, and subsequent repression during the civic-military dictatorship (1973-1990). In particular, it is of interest to highlight from a recent history approach, the assumption that during the 80's decade, it was implemented actions of political violence, as the instalation of the detention and torture center denominated "Cuartel Bahamondes", wich objective was to anihilate and exterminate the resistance actions. The methods includes the primary sources, files from the archbishopric of Concepción and testimonies as well as journalistic and academic secondary sources. The findings show the need to enphasise the value and resignify the narrations and local spaces of memory.
\end{abstract}

Key words: political violence perpetrate by State, Movimiento Izquierdista Revolucionario (MIR), civic -military dictatorship at Concepción, Cuartel Bahamondes

Recibido: 23 junio 2018 Aceptado: 19 agosto 2018

\footnotetext{
* Este artículo forma parte del proyecto Fondecyt de iniciación $\mathrm{N}^{\circ} 11170069$ "Memorias colectivas de lugares y/o sitios de memoria en Concepción: emociones desde los imaginarios locales vividos” (2017-2018). Investigadora responsable: Paula Tesche Roa.

** Co-autora, chilena, Doctora en Ciencias Humanas por la Universidad Austral de Chile, Facultad de Filosofía y Humanidades, Valdivia, Chile. Académica de la Facultad de Educación y Ciencias Sociales de la Universidad Andrés Bello, Concepción, Chile. paula.tesche@unab.cl

*** Co-autor, chileno, Magister en Historia por la Universidad de Concepción, Facultad de Humanidades y Arte, Concepción, Chile. Asistente de investigación proyecto Fondecyt de iniciación N¹1170069. jgonzalezalarcon1@gmail.com
} 
Paula Tesche - Javier González, Violencia política contra el MIR en Concepción, región del Biobío: Cuartel Bahamondes como centro de operación, detención y tortura en 1984, Izquierdas, 48, noviembre 2019:126-142

\section{Introducción}

En este apartado interesa, precisar algunos antecedentes que permiten clarificar esta investigación. En primer lugar, se aborda el macro contexto, que releva en la historia local la violencia política en Concepción, en el marco de la dictadura cívico militar (1973 - 1990), así como los efectos de la represión y la resistencia en la ciudad. En segundo lugar, se realizan precisiones en cuanto al enfoque, historia reciente, y el campo de investigación, a saber, la violencia política.

En un sentido general, en el transcurso de la historia chilena "Concepción se ha constituido en una de las zonas geográficas más importantes del país. Desde la guerra de Arauco, como línea fronteriza, en la cual las relaciones hispano-indígenas se constituían en un marco de referencia obligado de toda la región, pasando por su trascendencia durante el periodo independentista y años posteriores, hasta llegar al siglo XX, la región del Biobío así como el 'Gran Concepción'1 y la ciudad propiamente tal, han jugado un rol significativo en el proceso sociopolítico nacional"'. En dicho contexto, Alejandra Brito indica que la ciudad de Concepción y su entorno, puede ser examinada y/o estudiada durante el transcurso del siglo XX sobre la base de 3 aspectos fundamentales y significativos para la región. En primer lugar, la fundación de la Universidad de Concepción constituyéndose en un polo cultural e intelectual importante en la zona. El segundo aspecto hace referencia al proceso industrializador de mediados del siglo XX que gestó transformaciones sociales, económicas y urbanas, y por último, el quiebre producido por el golpe cívico militar de $1973^{3}$. Es precisamente este último punto el que da cuenta de las acciones de violencia y represión desplegadas una vez producida la intervención militar del 11 septiembre de 1973 en Concepción ${ }^{4}$.

El periodista James Whelan ${ }^{5}$ señaló en la misma mañana del martes 11 de septiembre de 1973, el rápido control que se llevó a efecto en la ciudad de Concepción, neutralizando a los altos dirigentes de

\footnotetext{
${ }^{1}$ Siguiendo el análisis realizado por el académico Hilario Hernández (1936 - 2010), el "Gran Concepción” es la conurbación urbana constituida por la ciudad de Concepción como centro de operaciones públicas y privadas; por el complejo portuario industrial siderúrgico y petroquímico Talcahuano-San Vicente; los espacios tradicionales de la loza y el vidrio Penco y Lirquén; Chiguayante y Tomé como centro textil; y las localidades de Coronel y Lota, como ciudades del carbón. En Hilario Hernández, "El gran Concepción: Desarrollo histórico y estructura urbana. Primera parte. Génesis y evolución: De las fundaciones militares a la conurbación industrial", Revista de Informaciones Geográficas, No 30,2001, 369.

2Danny Monsálvez, "Violencia y represión en un dispositivo local: Concepción, 11 de septiembre de 1973", Revista de Historia y Geografía, N²6, 2012, 57-80.

${ }^{3}$ Alejandra Brito, "Concepción: un antes y un después", Mario Garcés, Pedro Milos y Myriam Olguín (eds.), Memorias para un nuevo siglo. Chile, miradas a la segunda mitad del siglo XX, Santiago de Chile, LOM ediciones, 2000.

4 Tal como señala el Informe V alech (2004), las principales características de la represión cívico militar en la región, corresponden a la designación de jefes de Estado zonales, el extremo uso de la violencia, en especial tortura y maltrato físico, la importante participación activa de civiles, especialmente en zonas rurales, el uso de recintos de Carabineros y las fuerzas armadas, como centros de represión y tortura, y la habilitación de centros de reclusión masiva. También se señalan evidencias de frecuentes traslados de prisioneros en una misma ciudad de la región o entre ellas, de la constitución de campos de prisioneros en tres ciudades de la región (Chillán, Concepción y los Ángeles), inmediatamente luego de haber ocurrido el golpe de Estado y la presencia de recintos secretos.

5 James Whelan, Desde las cenizas. Vida, muerte y transfiguración de la democracia en Chile 1833-1988, Santiago de Chile, Editorial ZigZag, 1993.
} 
Paula Tesche - Javier González, Violencia política contra el MIR en Concepción, región del Biobío: Cuartel Bahamondes como centro de operación, detención y tortura en 1984, Izquierdas, 48, noviembre 2019:126-142

la Unidad Popular, los cordones industriales y la Universidad de Concepción ${ }^{6}$, sin disparar un solo tiro ${ }^{7}$ Ante esto, cabe interrogarse ¿Por qué era tan necesario para la Junta Militar este raudo y efectivo control de la ciudad? La respuesta radica en que el Gran Concepción y la Provincia de Arauco, se habían transformado durante el transcurso del siglo XX en una importante zona de orientación política de izquierda representada por obreros y estudiantes. La izquierdización se profundizó con la llegada de la Unidad Popular al gobierno, de manera que fue primordial para la dictadura socavar toda señal de levantamiento en su contra.

Aquella mañana del 11 de septiembre se comenzaron a divisar las tanquetas, patrullas militares y muchos efectivos de Carabineros. El temor se apoderó de quienes habían participado de algún modo u otro en el gobierno de Allende. Algunos testigos relatan haber visto pasar a los camiones militares con muchos civiles en dirección al Estadio Regional ${ }^{8}$.

Sin embargo, tras ocurrido el golpe existió una minoría que pensó en resistir a la acción militar. Testigos indican que hubo un tiroteo en el centro de la ciudad detrás de la tienda Falabella, generándose enfrentamientos entre los pocos que quedaron de la UP y militares, contradiciendo de esta manera lo expuesto por el periodista Whelan quien, como ya habíamos mencionado, argumentaba que el control rápido de Concepción se había efectuado sin disparar un tiro. No obstante aquello, otros testigos plantearon que todo eran rumores debido a que los medios estaban intervenidos ${ }^{9}$, haciendo creer que la izquierda poseía armas para efectuar enfrentamientos y resistir a la insurrección militar.

Así, cientos de detenidos fueron trasladados a la Cuarta Comisaria de Concepción, Estadio Regional, isla Quiriquina, Cárcel Publica de Concepción y Base Naval de Talcahuano ${ }^{10}$, en los cuales fueron constantes las humillaciones y vejámenes.

En la década de los 80 's en un periodo marcado por la violencia política institucionalizada, existieron lugares que implementaron acciones represivas a determinados partidos políticos y sus representantes. Uno de ellos, fue el Cuartel Bahamondes constituido en uno de los principales centros de detención y tortura, desde el cual se dirigió en 1984, la operación destinada a neutralizar y exterminar al Movimiento de Izquierda Revolucionaria (MIR), en todo el sur del país.

Considerando el período histórico, el enfoque que facilita una comprensión del tema es el de la historia reciente, que pone en valor el pasado cercano, abierto e inconcluso, cuyos efectos se extienden

6Pasada las 8 de la mañana fue rodeada por efectivos del Ejército, quienes automáticamente instalaron ametralladoras en algunos de los cerros aledaños. Se ocuparon las escuelas de Periodismo, Sociología, los hogares universitarios y Radio Universidad de Concepción, posteriormente utilizada como radio de las Fuerzas Armadas hasta diciembre de 1974. Por otra parte, no se encontraron armas. Tampoco hubo resistencia armada de parte de estudiantes y funcionarios. Las delaciones fueron recurrentes. En el recinto universitario, personal de la institución participó en la construcción y confección de las listas de empleados que debían ser arrestados. Existieron denuncias de funcionario en contra de otros. Todo académico y funcionario que tuvo militancia en la Unidad Popular o en el MIR fue separado/desvinculado de la institución. Mario Valdés, "El golpe de Estado del 11 de septiembre de 1973 en Concepción (Chile). Las voces de los testigos”, Cuadernos de bistoria, N³7, 2012, 159-191.

${ }^{7}$ Tal como se ha señalado "Entre los partidarios del gobierno depuesto predominó el desconcierto y el miedo. La poca resistencia que hubo fue esporádica, aislada, sin coordinación entre sí, y con una capacidad de fuego ineficaz frente a un ejército profesional cohesionado y, por añadidura, en pie de guerra" Informe Comisión Nacional sobre Prisión Política y Tortura, Santiago, 2004, 173.

8 Valdés, op.cit., 159-191.

${ }^{9} \mathrm{Ibid}, 177$.

${ }^{10}$ Algunas cifras en lugares significativos son: El Estadio Regional, en el mes de octubre de 1973 poseía una cantidad de 589 detenidos; isla Quiriquina,en la misma fecha reunía a 552 personas entre las cuales se cuentan mujeres y extranjeros; Cárcel Publica de Concepción, con 73 detenidos, divididos en 43 a disposición del Ejercito, 17 de la Armada y 13 condenados por Consejos de Guerra; y Base Naval de Talcahuano en noviembre del mismo año, mantenía recluido a 158 detenidos. Otros recintos fueron: Cárcel de Bulnes; Cárcel de Chillán; Comisaría de Carabineros de Arauco; Liceo Alemán del Verbo Divino, de los Ángeles; Liceo de Hombres de Los Ángeles; entre otros. Todos ellos fueron la primera parada de los detenidos antes de ser enviados al Estadio Regional, isla Quiriquina o Base Naval. María Eliana Vega, No hay dolor inútil. La iglesia de Concepción y su defensa de los derechos humanos en la región del Biobio entre 1973 y 1991, Concepción, Chile, 1999. 
hacia nosotros (presente). Por ende, se trata de un pasado actual que se encuentra en permanente proceso de actualización y que interviene en las proyecciones futuras ${ }^{11}$. Los mecanismos que utiliza esta perspectiva son la memoria y el testimonio ${ }^{12}$, recursos que también son considerados en este análisis. El campo de investigación al que atiende la historia reciente, es la historia del presente, historia actual, inmediata o muy contemporánea, cuyo objetivo es legitimar el pasado cercano ya mencionado. Desde este pasado cercano que está en constante proceso de actualización, la memoria se constituye en prácticas colectivas de rememoración que dan un sentido a lo ya acontecido. Por consiguiente, la supervivencia de actores y protagonistas se vuelve una regla fundamental de esta nueva forma de hacer historia, teniendo en cuenta además, que los testimonios utilizados deberán ser sometidos a crítica, ya que son la percepción de un individuo a través de su propia mirada ${ }^{13}$.

Ahora bien, el concepto de violencia política, entendido como campo de investigación, es un concepto poco trabajado en la historiografía nacional, y para no profundizar en un extenso debate teórico sobre el tema, nos limitaremos a algunas generalidades de este. El primero de ellos, aludido por Austin Turk, considera un punto de vista criminológico para señalar que en el plano de la legalización de normas, son los grupos que dominan los procesos de legalización, entendiendo este como el proceso de "hacer leyes", quienes transforman normas ilegales en normas legales obligatorias para otros grupos ${ }^{14}$. Se entiende entonces, a partir de lo enunciado, que, en una concepción vertical, la violencia política es ejercida desde arriba hacia abajo. Para el historiador Julio Aróstegui, la violencia política tiene una estrecha relación con el poder, ya que se desenvuelve en el ámbito de los conflictos políticos, donde una de las partes tiene la tendencia a imponerse sobre otra. De esta forma, la violencia se puede interpretar como aquel conflicto central de toda sociedad entre gobernantes y gobernados que mantienen una característica de verticalidad. Así, la violencia política se centra en el conflicto vertical de dominantes y subalternos, de arriba hacia abajo y de abajo hacia arriba ${ }^{15}$. En este mismo lineamiento, Jaime Talancón manifiesta que el concepto es una manera de articular la relación que se da entre:

a) Gobernados y gobernantes. (rebelión, asonada, insurrección, revolución)

b) Gobernantes y gobernados. (represión, persecución, tortura, dictadura)

c) Gobernados y gobernados. (guerra civil)

d) Gobernantes y gobernantes. I) conflicto interno (golpe de Estado, magnicidio, asesinato político), II) conflicto externo (entre líderes o jefes de Estado [guerra]) ${ }^{16}$

Si se consideran los aportes de Hannah Arendt sobre la guerra, último aspecto que queda de manifiesto entre corchetes, esta no es más que una vieja continuación de la política por medio de la violencia, argumentando al igual que Aróstegui, que existe una relación entre violencia y poder, en la cual

\footnotetext{
11 María G. Acuña, Archivos y memoria de la represión en América Latina (1973-1990), Santiago de Chile, LOM ediciones, 2016. ${ }^{12} \mathrm{La} \mathrm{historia} \mathrm{reciente} \mathrm{aún} \mathrm{es} \mathrm{motivo} \mathrm{de} \mathrm{debate} \mathrm{académico,} \mathrm{pues} \mathrm{tal} \mathrm{como} \mathrm{explica} \mathrm{Levín,} \mathrm{es} \mathrm{un} \mathrm{enfoque} \mathrm{que} \mathrm{posee} \mathrm{la} \mathrm{particularidad}$ de ser parte del mismo fenómeno que estudia. Al respecto, según la autora existen, "a grandes rasgos, dos maneras distintas de concebir lo reciente. En primer lugar, la Historia Reciente está definida por una temporalidad que se delimita por su relación de cercanía con el presente y su objeto de estudio se encuentra en permanente reconstitución por esa relación de coetaneidad entre el sujeto que estudia, el historiador, y su objeto de conocimiento, el tiempo reciente. Sin embargo, en su mayoría, la historiografía concuerda en que la especificidad de la Historia Reciente deviene de algo excesivo, excepcional y novedoso en la historia argentina, difícil de conceptualizar, pero aludido siempre a partir de algunos términos clave como violencia, represión clandestina, terrorismo de Estado, desaparecidos". Marcela Bello, Entrevista con Florencia Levín, 16 de marzo 2015. Recuperado de http://argentinainvestiga.edu.ar/

${ }_{13}$ Marina Franco y Florencia Levín, "El pasado cercano en clave historiográfica”, Marina Franco y Florencia Levín (eds.), Historia reciente. Perspectiva y desafíos para un campo en construcción, Buenos Aires, Paidós, 2007, 31-66.

14 Austin Turk, "La violencia política desde una perspectiva criminológica", Revista Sistema, No 132-133, 1996, 41-55.

15 Julio Aróstegui, "Violencia, sociedad y política". Ayer, N¹3, 1994, 9-39.

${ }^{16}$ Jaime Talancón Escobedo, "La violencia política”, Revista de la Facultad de Derecho de México, N²51, Vol. 59, 2009, $377-388$.
} 
Paula Tesche - Javier González, Violencia política contra el MIR en Concepción, región del Biobío: Cuartel Bahamondes como centro de operación, detención y tortura en 1984, Izquierdas, 48, noviembre 2019:126-142

Marx consideró al Estado como un instrumento de violencia en manos de la clase dominante ${ }^{17}$. De esta manera, para Tito Tricot el concepto comprende "la conjugación orgánica de elementos coactivos destinados a la preservación y/o consecución de intereses económicos y políticos. El concepto de coacción implica la coexistencia de actores sociales capaces de hegemonizar un momento histórico"18. Siguiendo con lo anterior, Adela Cortina argumenta que la violencia política es un medio que busca conseguir determinados objetivos. Así, la violencia surge cuando se fuerza a otros a que hagan lo que no quieren hacer de modo natural ${ }^{19}$, teniendo en consideración que es un medio para dominar a otros y establecer, cambiar o preservar un determinado orden social. Esta constante ya estipulada entre la relación de violencia y poder, desde un punto de vista de la psicología social, hace que la violencia política sea un tema complejo con consecuencias sociales, políticas y psicológicas, entre otras, de vital importancia para los seres humanos ${ }^{20}$.

Por último, una aproximación más pertinente para este tema de investigación es la de Jean Domenach, quien comprende a la violencia política como toda acción de dominación de un grupo o individuo por parte de otro, en la cual, el uso de la fuerza se convierte en la imposición de una libertad sobre la otra. En definitiva, la violencia política entonces, obedece un motivo especifico, y es el de dirigirse contra los opositores ideológicos, ya sea para que se abstengan de dirigirse contra el sistema o exterminarlos, atentando contra la política imperante ${ }^{21}$, y los medios de los cuales se vale son, la censura de la prensa, los secuestros, torturas, asesinatos, atentados, entre otros.

\section{Operación retorno}

En atención al enfoque de la historia reciente y la violencia política como campo de investigación, interesa aludir a acciones de resistencia y de represión del MIR, en el contexto histórico de la primera década de la dictadura y relevar la situación en el sur de Chile, en específico, en Concepción.

A principio del año 1976 habían comenzado a quedar en libertad desde las cárceles y campos de confinamiento en todo Chile -a través de la conmutación de las penas-, un número relevante de miristas ${ }^{22}$ que decidieron permanecer en el país y así sumarse a la rebelión. Por otra parte, considerando la ética política del MIR -quienes habían desarrollado la consigna de "no al asilo" - se logra cimentar la idea de quienes habían sido exiliados, de retornar al país mediante el Plan 78, también conocido como Operación Retorno. El partido además, estimaba que desde 1977 se había estancado la política represiva de los organismos de contrainsurgencia de la dictadura, por lo que era una buena ocasión para retomar lo que había quedado inconcluso tras el golpe de Estado de $1973^{23}$.

En dicho contexto, desde el exterior se comenzó a elaborar la idea de una contraofensiva ${ }^{24}$ como reacción a la represión dictatorial. Así, Nelson Gutiérrez ${ }^{25}$, segundo hombre en la jerarquía del MIR,

${ }_{17}$ Hannah Arendt, Sobre la violencia, Madrid, Alianza Editorial, 2005.

18 Tito Tricot, "Reflexiones sobre la violencia política", Araucaria de Cbile, N³4, Madrid, 1986. Edición electrónica www.blest.eu/cs/tricot86.html

${ }^{19}$ Adela Cortina, "Ética y violencia política", Revista Sistema, 132-133, 1996, 57-71.

${ }^{20 I d a l y ~ B a r r e t o ~ y ~ H e n r y ~ B o r j a, ~ " V i o l e n c i a ~ p o l i ́ t i c a: ~ a l g u n a s ~ c o n s i d e r a c i o n e s ~ d e s d e ~ l a ~ p s i c o l o g i ́ a ~ s o c i a l ", ~ R e v i s t a ~ D i v e r s i t a s, ~ N º 1, ~ V o l . ~}$ 3, 2007, 109-119.

21Jean Domenach, "La violencia”, Jean Domenach, et al. (eds.), La violencia y sus causas, París, Editorial UNESCO, 1981, 33-45.

${ }^{22}$ No se ha podido establecer la cantidad de estos.

23 Robinson Silva, Resistentes y clandestinos: La violencia politica del MIR en la dictadura profunda 1978-1982, Concepción, Editorial Escaparate, 2011; e Igor Goicovic, Movimiento de Izquierda Revolucionaria, Concepción, Editorial Escaparate, 2012, p. 59.

${ }^{24} \mathrm{El}$ MIR buscaba generar una reacción ante la ofensiva represiva de la dictadura pinochetista, mediante la formación militar de centenares de militantes (en Cuba, Libia, Vietnam, Argelia, entre otros), el regreso clandestino a Chile y la implementación de una guerrilla rural.

25 Sociólogo de profesión. Militante del Movimiento de Izquierda Revolucionaria, miembro del Comité Central y máximo dirigente del MIR en el exterior en los años de dictadura. En su juventud ocupó cargos de importancia en la Universidad de 
Paula Tesche - Javier González, Violencia política contra el MIR en Concepción, región del Biobío: Cuartel Bahamondes como centro de operación, detención y tortura en 1984, Izquierdas, 48, noviembre 2019:126-142

anunció el inició de la denominada Operación Retorno desde La Habana, manifestando que "el partido requiere hoy concentrar y centralizar en Chile, en el frente, el máximo de su capacidad de dirección, de organización, el máximo de su capacidad para el trabajo de masas y de la realización de la línea militar"26. De esta manera, el Movimiento de Izquierda Revolucionaria debía promover la lucha contra la dictadura pinochetista y retomar el combate en las calles de Santiago, Valparaíso y Concepción ${ }^{27}$. Por consiguiente, en 1978, luego del entrenamiento recibido en Cuba, la mayoría de los miristas regresó a Europa para poder recibir las últimas instrucciones y la documentación falsa para reingresar a Chile. No está demás destacar, que un número no precisado de miristas que formaron parte del Plan 78, habían combatido en Nicaragua, El Salvador y Angola, mientras que otros recibieron entrenamiento en Corea del Norte, Yemen del Norte y Libia.

La estrategia del partido consintió en primer lugar, intentar rearticular el movimiento sindical ${ }^{28}$ y por otra parte, activar la Guerra Popular ${ }^{29}$. En este segundo punto, se sucedieron una gran cantidad de atentados realizados por miembros del MIR a lo largo del país. El 23 de abril de 1978 una bomba atentó contra la vida del teniente del Ejército Luis Caveric Muñoz, un ex miembro de la DINA e integrante activo de la Unidad Antiexplosivos de la CNI, mientras intentaba desactivar el aparato explosivo ${ }^{30}$. En junio de 1979, según consignaron medios oficiales, dos miristas -Alberto Salazar Briceño e Iris Vega Bizama- mueren en la ciudad de Concepción al explotarles una bomba que transportaban hacia las dependencias de Radio Nacional. En los convulsionados años 80's31 los atentados aumentaron significativamente, marcados por los constantes asaltos bancarios -Banco Concepción, Banco de Chile y

Concepción cómo la Presidencia de la FEC. Tras su exilio vuelve al país en 1990. Muere en 2008 tras un cáncer hepático a la edad de 64 años.

${ }^{26}$ Agregando además "Hay que concentrar esa experiencia, esos cuadros, esos hombres en el frente. Esa es la principal tarea de la retaguardia. Necesitamos preparar esos hombres, esos cuadros, los combatientes para la fase de la lucha que comienza. Esa es la orden del día: de la resistencia y la lucha revolucionaria. Este es un deber histórico y exigencia perentoria de nuestra moral de clases". Manuel Salazar, Las letras del horror, Tomo II: La CNI, Santiago de Chile, LOM Ediciones, 2012, 51.

${ }^{27}$ Idem.

28 Ver revista El Rebelde de 1977-1978; e Igor Goicovic, "Pueblo, conciencia y fusil. El Movimiento de Izquierda Revolucionaria MIR y la irrupción de la lucha armada en Chile (1965-1990)", Pablo Pozzi y Claudio Pérez (Editores), Por el camino del Che. Las guerrillas latinoamericanas, 1959-1990, Buenos Aires, Imago Mundi, pp. 203-242.

${ }^{29} \mathrm{Al}$ respecto, siguiendo el concepto acuñado por Mao Tsé-Tung sobre Guerra Popular, o también conocida como Guerra Popular Prolongada, cuya estrategia era mantener el apoyo de la población, el MIR intentó rearticular el movimiento de trabajadores, pobladores y estudiantes, manifestando que en estos movimientos se encontraban los potenciales revolucionarios que harían frente a la dictadura. De esta manera, pos golpe de Estado, el MIR concibió al Movimiento de Resistencia Popular como la herramienta capaz de conectar a la vanguardia con las masas, desarrollando movilizaciones populares como un paso previo a la ofensiva militar contra la dictadura, tanto en las zonas rurales como urbanas. Según Goicovic, "el objetivo fundamental de este diseño era desarrollar el poder político y militar de la clase obrera y el pueblo para derrotar a los enemigos de clase y concretar sus objetivos históricos. En ese contexto, la propaganda armada se convertía en el nexo entre la situación de las fuerzas populares y la orientación estratégica". Goicovic, op. cit., 60.

30 Goicovic, op. cit., 62.

31 Algunos autores que han periodizado los 17 años de dictadura sostienen que: entre 1973-1975, se desarrolló la represión más brutal, generalizada y sistemática en contra de la cúpula central de la Unidad Popular, así también a los movimientos sociales; 1976-1981, se vislumbra la reorganización y rearticulación de los movimientos sociales, emergiendo las primeras expresiones de organización social, principalmente en el mundo poblacional; 1982-1986, en un contexto de crisis económica y de ausencia de vías de expresión, la población social crece y busca las maneras de manifestarse. Se trata entonces, de la radicalización del movimiento poblacional y del incremento de la represión dictatorial, convirtiendo esta etapa en la segunda de mayor represión de la dictadura cívico-militar; y 1987-1990, los intereses se vuelcan al plebiscito de 1988. Ver Mario Garcés y Gonzalo de la Maza, La explosión de las mayorías. Protesta Nacional 1983-1984, Santiago de Chile, ECO, 1985; y Mónica Iglesias, Rompiendo el cerco. El movimiento de pobladores contra la dictadura, Santiago de Chile, Ediciones Radio Universidad de Chile, 2011. 
Paula Tesche - Javier González, Violencia política contra el MIR en Concepción, región del Biobío: Cuartel Bahamondes como centro de operación, detención y tortura en 1984, Izquierdas, 48, noviembre 2019:126-142

Banco de Crédito e Inversiones- y supermercados -AGAS- con el objetivo de recaudar fondos para lograr sostener sus operaciones ${ }^{32}$.

El día 15 de julio de 1980 fue asesinado el Coronel Roger Vergara, quien se desempeñaba como director de la Escuela Nacional de Inteligencia del Ejército. Este suceso fue considerado como uno de los mayores golpes efectuados por la Fuerza Central ${ }^{33}$ del MIR, y acaba de alguna manera, creando la idea en la oposición, de que el MIR mantenía una fuerte presencia militar en el país, permitiendo concluir que la Operación Retorno estaba dando resultados congruentes ${ }^{34}$. En ese contexto, a fines de 1980 muere Roberto Rojas ${ }^{35}$. El sujeto fue asesinado en su casa y junto a esta se encontraron algunos volantes que decían "lo matamos por ser agente de la CNI, torturador e infiltrado. Milicias Populares de la Resistencia" 36 .

En el Biobío también se registraron acciones milicianas. Con la intención de sabotear un transporte de madera y carbón en homenaje al aniversario de la CUT, el comando "Luís Pincheira" incendió una locomotora en un paso bajo nivel. También, el comando "María Galindo" ${ }^{77}$ colocó lienzos y distribuyó panfletos en un policlínico de Chiguayante Sur con la consigna "A Quebrar la Dictadura". En la ciudad de Concepción se atacó la Empresa Eléctrica del Sur, y en Coronel el supermercado Las Brisas. Luego de la destrucción de algunos transformadores de la CGEI, hubo cortes de luz en la comuna de San Pedro de la Paz, Coronel y camino al poblado de Santa Juana.

De esta forma, las operaciones realizadas, ya sea tomas de calles, atentados incendiaros, asesinatos de agentes de la CNI, asaltos, y colocación de lienzos llamando a la resistencia ${ }^{38}$, buscaban demostrar que el MIR se encontraba activo y con cuadros preparados para enfrentar a la dictadura. Por otro lado, la revolución Sandinista y los avances de la guerrilla guatemalteca y salvadoreña demostraban que la "vía armada" aún conservaba vigencia, dejando en claro que el accionar militar revolucionario era viable para poder derrocar al régimen pinochetista ${ }^{39}$. El Partido Comunista por su parte decide poner en práctica su Política de Rebelión Popular de Masas (PRPM), autorizando el ingreso de oficiales militares chilenos formados en Cuba y que habían participado en el triunfo de la revolución sandinista. Desde 1975 un centenar de jóvenes comunistas también eran formados en el extranjero, no sólo en Cuba, sino también en Hungría, Rumania, en la RDA, y en otros países del orbe socialista ${ }^{40}$.

\footnotetext{
32 Ver Goicovic op. cit., 63-68. El autor describe algunos atentados bancarios y la cobertura mediática de los medios de prensa proclives a la Dictadura Cívico-Militar, como El Mercurio y La Tercera, quienes de alguna manera, tergiversaban u omitían el verdadero accionar del movimiento revolucionario.

${ }^{33}$ La Fuerza Central del MIR (FC) se constituyó en el contexto del Plan 78 mediante elementos exteriores como también con militantes que habían permanecido en el país después del golpe de Estado, estableciéndose como el principal núcleo especializado de combatientes del partido. La FC actuó realizando apagones y numerosas acciones de Resistencia bajo la dictadura. Ver: Sergio Hernández y Eduardo Medina, La experiencia de la Fuerza Central del MIR 1979-1983: Vivencias y reflexiones de dos sobrevivientes, Concepción, Ediciones Escaparate, 2017.

34 Robinson Silva, op. cit., 117; e Igor Goicovic, op. cit., 67-68

${ }^{35} \mathrm{Tal}$ como ha sido señalado "Rojas, de 34 años, tenía una trayectoria conocida. Desde el nacimiento de Patria y Libertad se había mostrado como uno de los miembros más activos de los escuadrones nacionalistas de choque. Derrocado el gobierno de Salvador Allende, Rojas había sido enganchado como colaborador de los servicios de seguridad del régimen militar”. Salazar, op. cit.,109

36Idem.

37 Ambos comandos tomaron los nombres de víctimas de la dictadura: María Galindo, detenida desaparecida en 1976 y Luis Pincheira, asesinado en 1981 en Santiago.

38 Para más detalles sobre las operaciones realizadas por el MIR, ver: Silva, op. cit:; José Palma, El MIR y su opción por la Guerra Popular: Estrategia político-military experiencia militante 1982-1990, Concepción, Editorial Escaparate, 2012; Cristian Pérez, "Historia del MIR. Si quieren guerra, guerra tendrán”, Estudios Públicos, N91, 2013, 5-44; Eduardo Arancibia, Las milicias de la resistencia popular: El MIR y la lucha social armada en dictadura 1979-1984, Concepción, Ediciones Escaparate, 2015.

${ }^{39}$ Julio Pinto, Rolando Álvarez y Verónica Valdivia, Su revolución contra nuestra revolución. Vol. II. La pugna marxista-gremialista en los ochenta, Santiago de Chile, LOM Ediciones, 2008, 89.

40 Salazar, op. cit., 153.
} 
El MIR se propuso establecer un destacamento guerrillero en el sur del país. Así, el mirista apodado "José Manuel", quien había recibido entrenamiento militar en Cuba y en la RDA, se dirigió hacia el sur de Concepción para hacerse cargo de la instalación de uno de estos destacamentos. Por otra parte, Salvador Sandoval Torres, hijo de un pescador de Tomé, ingresó al país por Argentina en 1978 para asumir la célula mirista en Concepción. Sin embargo, tras constantes represiones ejercidas en su contra, se traslada en julio de 1981, junto a su esposa Aída Cerro, a la ciudad de Santiago siendo asesinado el 17 de agosto del mismo año, en una emboscada en la calle Sargento Rojas esquina Vanguard de la Población Risopatrón ${ }^{41}$.

En 1981 la fase de la Operación Retorno instaló dos frentes guerrilleros en el sur: uno en Neltume -localidad ubicada en la cordillera de la Región de Los Ríos, perteneciente a la comuna de Panguipulli- y otro en Nahuelbuta, en la provincia de Malleco ubicada en la zona costera de Arauco. El diseño estratégico incluía entonces, introducir nuevas bases para lograr reconstruir el MIR en Valdivia, Temuco y Concepción. De esta manera, la lucha de la resistencia se decidía no sólo en Santiago y Valparaíso, sino también en el sur de Chile. Sin embargo, la fuerza militar destinada a esta zona no alcanzó a inaugurarse cuando fue completamente desbaratada. El aislamiento y las probables delaciones de algunos campesinos en Neltume, desembocaron en que el día 27 de junio de 1981 se detuviera al núcleo guerrillero allí asentado. Misma suerte, aunque menos trágica, fue la experiencia guerrillera en Nahuelbuta, la que tampoco había arrojado resultados positivos ${ }^{42}$.

Los dispositivos represivos del régimen buscaron necesariamente actuar en varios niveles: en primer lugar, golpear con la mayor fuerza posible a la resistencia armada, mediante asesinatos a militantes miristas y comunistas, montajes y falsos enfrentamientos, y por otro lado, atemorizar a las renacientes organizaciones sociales e impedir la exteriorización del descontento. En este plano, el MIR sabía que era una buena estrategia aprovechar el malestar social y decidió recurrir a los sectores obreros, juveniles y poblacionales.

A comienzos de abril de 1981 la Policía de Investigaciones -PDI- anunció la ampliación de los integrantes de la Brigada Especial o también conocida como Comando Antisubversivo, a más de cien uniformados que se abocaron primordialmente a la captura de lo que para ellos era el verdadero jefe del aparato militar del MIR, el ex aviador Arturo Villavela, conocido como el "Coño Aguilar"43. De esta forma, el 7 de septiembre de 1983, el MIR fue víctima de una "operación de exterminio" por parte de la CNI, quienes abatieron a Villavela y a su núcleo más cercano: Alejandro Salgado, Lucía Vergara, Sergio Peña y Hugo Ratier, en los operativos en las calles Fuenteovejuna -en las Condes- y Janequeo -en Quinta Normal-. Este golpe ocurre a escasos días de que un destacamento de la dirección del MIR asesinara al intendente de Santiago, el general Carol Urzúa ${ }^{44}$.

Los historiadores Julio Pinto y Sebastián Leiva argumentan que el año 1981 marcó un punto crucial en la Operación Retorno. No obstante, con la muerte del "Coño Aguilar" en 1983 el Plan 78 decae aún más, marcando su segunda derrota ${ }^{45}$. Ese mismo año cae gran parte de la Fuerza Central del MIR y con ella, la posibilidad de lograr pasar a una forma de Resistencia Armada con mayor efectividad y

\footnotetext{
${ }^{41}$ Lisandro Salvador Sandoval Torres, en www.memoriaviva.com

42Pinto, op. cit., 146; y Goicovic, op. cit., 71-72

43 Salazar, op. cit., 115.

${ }_{44}$ Alejandra Matus, "La victoria de la CNI sobre el MIR", en http://www.casosvicaria.cl; Según Carlos Sandoval, la muerte de Villavela marca un episodio que es considerado como la segunda derrota militar del MIR. Por tal motivo, dentro de su trabajo divide en dos momentos el estudio realizado, en primer lugar la etapa de la resistencia armada activa. Es decir, desde la nueva propuesta insurreccional del MIR, hasta la muerte de Villavela, y un segundo momento que comprende cómo el MIR discutió internamente; cuáles fueron las diferencias políticas y cómo buscó de alguna manera superar los fortísimos golpes represivos que diezmaron sus recompuestas fuerzas. Carlos Sandoval, Movimiento de Izquierda Revolucionaria, 1980-1986, Tomo IV, Santiago de Chile, Editorial Quimantú, 2014.

${ }^{45}$ Pinto, op. cit.
} 
ofensiva. De esta manera, el partido llegaba al período de las protestas nacionales $(1983-1986)^{46}$ seriamente debilitado ${ }^{47}$.

Un año más tarde, en el Pleno del 84, el MIR buscó generar nuevos levantamientos locales que mantuvieran como tarea anexa, la formación de nuevas milicias. Sin embargo, "mientras esto ocurría en Santiago, la entrada en acción en las provincias sureñas de una fuerza más permanente denominada 'Fuerzas Armadas de Resistencia Popular' fue rápidamente neutralizada mediante un operativo que culminó el 23 de agosto de 1984 [...]"48.

\section{Operación Alfa Carbón}

A comienzos de 1984 se dio inicio a la denominada Operación Alfa Carbón 1 "cuando Jorge Mandiola Arredondo ${ }^{49}$, jefe de la CNI de Concepción informó a su superior Marcos Spiros Deprich Miranda ${ }^{50}$, jefe de la División Regionales CNI, que ya existían datos suficientes para acreditar la presencia de una estructura subversiva en la zona: el Teatro de Operaciones Sur (TOS) del Movimiento de Izquierda Revolucionario (MIR)" 51 . Los informes entregados por Mandiola contenían datos específicos de miristas, como, por ejemplo, nombres, domicilios, organigrama del partido, entre otras cosas.

De esta forma, y con la recopilación de datos realizada, Deprich desde Concepción -Cuartel Pedro de Valdivia- y Álvaro Corbalán desde Santiago -Cuartel Borgoño- fueron los encargados de comandar la operación que buscaba la desarticulación definitiva de la jefatura del MIR en el sur de Chile. Una columna publicada el 25 de agosto de 1984 en diario El Sur argumentaba que la finalidad de este operativo era desbaratar los planes "terroristas" que el movimiento tenía proyectado realizar en septiembre de ese año ${ }^{52}$. Así, con las "piezas puestas en su lugar", Deprich y Mandiola dirigieron una reunión el día previo a efectuar la operación Alfa Carbón, en la cual participó todo el mando de la CNI, incluido Corbalán. En ella se decidió a quienes había que detener y a quienes eliminar, marcando con una cruz la foto de estos últimos.

El operativo de la CNI realizado los días 23 y 24 de agosto de 1984 en las ciudades de Los Ángeles, Valdivia y Concepción dejó el saldo de siete miristas muertos y más de una docena de encarcelados ${ }^{53}$. Así, en la ciudad penquista, un equipo liderado por Luís Hernán Gálvez Navarro se apostó

\footnotetext{
${ }^{46}$ Sobre las Protestas Nacionales ver: Guillermo Campero, Entre la sobrevivencia y la acción politica: Las organizaciones de pobladores en Santiago, Santiago de Chile, Ediciones ILET, 1987; Garcés, op. cit;; Mario Garcés y Sebastián Leiva, El golpe en la Legua: Los caminos de la bistoria y la memoria, Santiago de Chile, LOM Ediciones, 2005; Patrick Guillaudat y Pierre Mouterde, Los movimientos sociales en Chile: 1973-1993, Santiago de Chile, LOM Ediciones, 1998; Pinto, op. cit.; José Weinstein, Los jóvenes pobladores en las protestas nacionales (1983-1984), Santiago de Chile, CIDE, 1989; e Iglesias, op. cit.

47 Goicovic manifiesta que "más de 20 militantes resultaron muertos en el transcurso del bienio 1980-1981, en enfrentamientos armados, reales o simulados. La mayoría de ellos pertenecía a los comandos especializados de la organización. Otros resultaron detenidos y fueron objeto de largas condenas a prisión dictaminadas por tribunales militares". Sin embargo, durante este ciclo el MIR realizó una contribución fundamental a la reanimación del movimiento de masas, colocando en evidencia que si bien la Dictadura constituía un enemigo poderoso, no era invencible. Goicovic, op. cit., 71-73

48Pinto, op. cit., 122.

${ }^{49}$ Algunos antecedentes sobre Mandiola son: "Jefe Brigada Regional Concepción de la CNI. Dirigió el inicio del trabajo de inteligencia y secundo a Deprich en el comando del operativo Alfa Carbón, fue visto tanto en Plaza el Ancla como en Vega Monumental", en https://ciperchile.cl/2013/06/04/alfa-carbon-1-la-operacion-albania-del-sur/

${ }^{50}$ Respecto a Deprich: "En su calidad de Jefe de la División Regionales de la CNI, comandó el operativo Alfa Carbón desde el Cuartel Pedro de Valdivia de Concepción [...]”, en https://ciperchile.cl/2013/06/04/alfa-carbon-1-la-operacion-albania-del$\underline{\text { sur/ }}$

51Extraído de https://ciperchile.cl/2013/06/04/alfa-carbon-1-la-operacion-albania-del-sur/

52Diario El Sur, 25 de agosto de 1984.

53 La violencia de la operación causó la muerte de: Luciano Aedo, Mario Lagos y Nelson Herrera en Concepción; Mario Mujica en Los Ángeles; y Rogelio Tapia, Raúl Barrientos y Juan José Bancompte en Valdivia. De los detenidos en el Cuartel Bahamondes
} 
a las 11 de la mañana en la localidad de Hualpencillo. Pasado las 12 del mediodía es asesinado en un falso enfrentamiento, Luciano Aedo, 34 años, padre de cuatro niños, miembro del MIR y dirigente del TOS. A las 16 horas del mismo día fueron asesinados frente a la Vega Monumental, Mario Octavio Lagos Rodríguez de 34 años, padre de 3 hijos, miembro del MIR, encargado militar del TOS y uno de los pocos sobrevivientes de Neltume y Nelson Adrián Herrera Riveros de 30 años de edad, padre de 1 hija, miembro del MIR y encargado político militar del TOS. Ambos mueren en falsos enfrentamiento.

Con respecto a los hechos recientemente relatados, se declaran dos versiones. Por un lado, la oficial, es decir, aquella información que circuló en los medios de comunicación oficialista y proclive a la dictadura -El Sur, Crónica, Diario Color, El Mercurio, entre otros-, quienes anunciaron que las muertes se debieron a enfrentamientos, y por otra parte, la de los testigos que contaron lo sucedido a los medios de oposición -Revistas Cauce, Análisis, Apsi, entre otras-, manifestando el homicidio de jóvenes miristas por el sólo hecho de pensar distinto.

De esta manera, la información oficial ${ }^{54}$ entregada por la Intendencia de la Octava Región afirma que la muerte de Aedo se debió a que la CNI había detectado el día 23 de agosto de 1984 a un sujeto sospechoso, quien al percatarse de la presencia de los agentes extrajo una pistola de $9 \mathrm{~mm}$, con la que abrió fuego hiriendo a un funcionario. Estos últimos al intentar repeler el ataque dieron muerte al "violentista". No obstante, testigos argumentaron que el operativo comenzó temprano en la mañana, en el cual se tendió un cerco en el sector a través de una gran cantidad de personal de civil y más de diez vehículos apostados en el lugar. Así "Desde estos vehículos le dispararon por la espalda. Tras caer herido, aseguraron los testigos, los funcionarios de seguridad lo habían rematado, esparciendo luego panfletos. A los pocos minutos Televisión Nacional filmaba todo el cuadro" 55 . Cabe preguntarse entonces ¿TVN estaba "casualmente" allí? Por otra parte, la autopsia indicó que el joven asesinado había recibido 7 impactos de bala, 4 de ellos en la espalda, 1 en la cabeza, 1 en la mano izquierda y 1 en el píe izquierdo ${ }^{56}$.

Ampliando el operativo, anunciaba la prensa oficialista, se capturan otros dos "terroristas" vinculados con Aedo. Estos al darse cuenta que eran seguidos, abordaron un taxibus de la línea Concepción-Talcahuano, en el cual procedieron a tomar de rehenes a los pasajeros. La persecución culminó cuando fueron interceptados en calle 21 de mayo a la altura de la Vega Monumental, frente a la población Lorenzo Arenas. En este lugar se produjeron intercambios de disparos, falleciendo uno de los miristas en el lugar y el otro en el traslado a la asistencia pública ${ }^{57}$.

No obstante aquello, algunas personas dieron cuenta de que el bus había sido seguido por José Abel Aravena Ruiz, suboficial de carabineros y miembro de la brigada azul ${ }^{58}$, desde que salió del terminal hasta llegar a la "Vega Monumental". Según testigos que informaron de la presencia de Carabineros en el lugar previo a lo sucedido, el tránsito con dirección hacia Concepción estaba cortado desde antes que se detuviera el vehículo de la locomoción colectiva. Los disparos de parte de personal policial se efectuaron antes de que los pasajeros descendieran del taxibus. Mario Lagos fue baleado con los brazos en alto, mientras que Nelson Herrera fue capturado vivo y posteriormente ejecutado ${ }^{59}$.

Un testigo manifestó que:

encontramos a Alejandro Bernstein Rother, Ignacio Vidaurrazaga, María Arroyo Soto, Patricia Zalaquett Daher, María Aránguiz Ruz, María Chacaltana Pizarro, Miguel Barriga Gutiérrez y, Mónica del Pilar Martínez Barra.

54 Revista Cauce, $\mathbf{N}^{\circ} 21$, septiembre 1984; y revista Apsi, № 151, agosto 1984, 15.

55 Revista Cauce, N²0, agosto 1984, 2.

${ }^{56}$ Causa Rol N746-84, citado de https://ciperchile.cl/2013/06/04/alfa-carbon-1-la-operacion-albania-del-sur/

${ }_{57}$ Revista Cauce, N²1, septiembre 1984.

58 Las agrupaciones represivas encargadas de la desarticulación de la izquierda de los años 80 se identificaron con colores. La brigada café, dirigida por Alejandro Manuel Concha, estuvo a cargo del exterminio del MAPU y de la Izquierda Cristiana; la Brigada Amarilla, dirigida por Patricio Castro Muñoz, al Partido Socialista; la Brigada Verde, dirigida por Pedro Guzmán Olivares, al Partido Comunista y al FPMR; y la Brigada Azul, dirigida por Aquiles González Cortés, al Movimiento de Izquierda Revolucionaria.

${ }^{59}$ Diario El Sur, 24 de agosto de 1984, 8. 
“[...] Mario, que bajó totalmente rendido cuando hicieron bajar a la gente, bajó toda la gente y finalmente bajó Mario con los brazos en alto"

"El otro compañero fue ingresado a esa camioneta, yo vi cuando iba herido y lo subieron, iban cuatro personas, cuatro CNI [...]" 60 .

En consecuencia, Aravena junto con Sergio Mateluna Pino, Luis Andaur Leiva y un cuarto agente sin identificar, condujeron a Nelson Herrera camino a Santa Juana, lugar en el cual lo ejecutaron, siendo Andaur quien le disparó. La autopsia indicó que fue muerto producto de un disparo en el cráneo a muy corta distancia y en circunstancias que ya se encontraba esposado, lo que se pudo desprender de las marcas dejadas en sus muñecas ${ }^{61}$. Por su parte, el chofer del taxibus, Pedro Aguayo, declaró:

"Me dirigí hacia él y estuve a un metro de él. En ese mismo momento llegaron dos agentes que lo levantaron de los brazos. El caído abrió los ojos y me miró de frente. No tenía sangre en ninguna parte del cuerpo, a excepción de un rasmillón en la parte de la sien derecha, que pudo haber sido a causa de la caída o del roce de una bala [...] Los dos hombres que se habían acercado lo tomaron fuertemente de los brazos, lo incorporaron y dijeron que estaba herido y había que llevarlo al hospital"62.

A la misma hora de estos presuntos "enfrentamientos" o con posterioridad a los mismos, se produjeron detenciones y allanamientos en distintos sectores de la ciudad. A las 12:30 fueron detenidas las miristas Lidia Barra y su hija Mónica del Pilar Martínez Barra de tan solo 15 años. Una hora más tarde se realizó otro operativo en Ongolmo 988, sector Remodelación Paicaví, y a las 17:00 hrs se detuvo por personal de civil en Villa El Recodo, camino a Santa Juana, a Patricia Zalaquett, esposa de Nelson Herrera, y su hija Javiera Herrera Zalaquett de 3 años ${ }^{63}$. En estos allanamientos manifestó la prensa oficial, se encontraron armas, explosivos y material subversivo.

Posterior a lo sucedido, monseñor José Manuel Santos, arzobispo de Concepción, pidió la presencia de un Ministro en Visita para que investigara las tres muertes ocurridas en la ciudad de Concepción y, los múltiples allanamientos y detenciones violentas realizadas por civiles armados, quienes se identificaban con brazaletes amarillos. Sin embargo, frente a la negativa, presentó todos los antecedentes que pudo recopilar a la Corte Suprema.

Ese 23 de agosto culminaba la cacería y asestaban seguramente, el último y más certero golpe estructural a la capacidad del MIR como organización clandestina a nivel nacional. Los agentes de la CNI manifestaban que el Movimiento había estado por varios meses inactivo, pero que sabían que se hallaba en una etapa de reorganización de fuerzas, buscando la incorporación de un nuevo contingente. Sabían de la existencia de varias células miristas en la zona de Concepción, por lo que habían planeado desbaratarla ${ }^{64}$.

\section{Cuartel Bahamondes}

Esta sección, tiene como objetivo vincular la violencia política contra el MIR con un recinto específico de la ciudad de Concepción destinado a tales efectos. Para ello, se alude al Cuartel Bahamondes como un centro gestor de violencia para desarticular y desbaratar el MIR, especialmente el año 1984.

\footnotetext{
${ }^{60}$ Bambina Carrasco y Jennifert Fuentes, Intervención Tanatologica del Estado en Lorenzo Arenas. La Operación Alfa Carbón y sus consecuencias, Tesis para optar al título profesional de Trabajador (a) Social, Universidad del Bío-Bío, Concepción, 2016 , p. 66. 61 Informe de la Comisión Nacional de Verdad y Reconciliación, Vol. I, Tomo 2, 1996, 998.

62 CIPER Chile y diario El Sur, 24 de agosto de 1984, 8.

${ }^{63}$ Revista Solidaridad, No 184, septiembre 1984, 20.

${ }^{64}$ Diario El Sur, 25 de agosto de 1984.
} 
Paula Tesche - Javier González, Violencia política contra el MIR en Concepción, región del Biobío: Cuartel Bahamondes como centro de operación, detención y tortura en 1984, Izquierdas, 48, noviembre 2019:126-142

Como se consigna en el Informe Comisión Valech (2004), este cuartel recibió diversos nombres, además de Cuartel Bahamondes, por el nivel de violencia y los procedimientos que se usaban para torturar. De esta forma, también es denominado "Casa de la Risa", como una ironía del daño que producían los maltratos y "Casa de la Música", pues era frecuente que los torturadores usaran música para evitar que los gritos de quienes torturaban fuesen oídos en el exterior.

El Cuartel tiene una gran relevancia en el contexto de los 159 centros de detención y tortura consignados en la Región, pues fue el único recinto de la CNI65

"reconocido oficialmente por las autoridades militares de la época como lugar de detención en el Decreto Supremo N 594, en junio de 1984. En este caso existieron también personas que aseguran que fueron conducidas a la Base Naval de Talcahuano por personal de la CNI luego de detenerlas. En este recinto permanecieron un breve período, sometidos a interrogatorios y torturas. Luego, fueron trasladados a otros recintos" $" 66$.

El Cuartel ubicado en las intersecciones de las calles Bahamondes con Pedro de Valdivia, fue "forzosamente" reconocido debido a que en el año 1984 la ministra María Cristina Aqueveque inspeccionó el lugar, acogiendo un recurso de amparo presentado por Yolanda Manríquez jueza del 11 Juzgado Civil de Santiago y madre de uno de los detenidos - del 23 de agosto de 1984 en la operación Alfa Carbón- en el lugar, el mirista Ignacio Vidaurrázaga. Lo cierto, es que cuando la ministra ingresó los detenidos habían sido sacados por otra puerta, pues el Cuartel tenía entrada tanto por Pedro de Valdivia como por Bahamondes ${ }^{67}$. Otra característica del Cuartel, es que como informa la Comisión, éste era un lugar de paso, entre uno y diez días, luego de ello los detenidos eran trasladados a otros centros de reclusión de la región o del país.

Las detenciones y reclusiones en este centro tenían tres características relevantes. En primer lugar, contaban con un gran despliegue de los servicios de inteligencia, en el sentido de los recursos personales y económicos invertidos. En segundo lugar, se realizaban con gran violencia, caracterizándose por maltratos extremos y torturas muy intensas y, finalmente, las acciones represivas fueron dirigidas a los máximos dirigentes de los principales partidos de la época, MIR y Partido Comunista.

Respecto al despliegue de los Servicios de Inteligencia, cabe señalar, que incluso antes de las detenciones se implementaba un completo y exhaustivo dispositivo de espionaje y seguimiento, tal como consta en el siguiente testimonio de un detenido en este lugar:

"Yo no sabía de Bahamondes y los de Conce tampoco. Nosotros no teníamos contrainteligencia. Nos damos cuenta que nos vienen siguiendo y en vez de hacer algo dejamos pasar el tiempo. Nos damos cuenta...por ejemplo yo vivía en un departamento y estaba casi sin nada y voy con la pareja de ese momento, estamos esperando [locomoción] y el colectivo llega al tiro y viene justo para que subamos los dos y nosotros nos dimos cuenta que eso era absolutamente raro y que nos habían puesto una línea de colectivo...en otro lugar pusieron un quiosco. Te transformaban todo. Entonces, además como tú no eras del barrio, tú decías: ¡qué raro la vecina recogiendo la basura ahora! Nos dábamos cuenta que teníamos control"68.

\footnotetext{
${ }^{65}$ No obstante, el Cuartel estaba a cargo del Jefe de la CNI de Concepción, Mayor Jorge Mandiola Arredondo, los testimonios dan cuenta de la participación en la detención y tortura del Servicio de Inteligencia Regional de Carabineros (SIRE), el Ejército y la Armada de Chile, en colaboración directa con civiles.

66 Informe de la Comisión Nacional sobre Prisión Política y Tortura, 2004, 356.

67 Vega, op. cit.

${ }^{68}$ Información comunicada en entrevista personal el 25 de marzo de 2018. Tal como fue solicitado por el entrevistado su nombre es confidencial.
} 
Durante la detención, el despliegue de recursos consideraba el uso de diversos medios de transportes, camiones, autos, avionetas, etc. así como disposición de implementos y maquinarias de tortura y especialmente, armas de distintos tipos y alcance. Al respecto, el testimonio de la detención de un integrante del MIR confirma lo anterior: "Cuando yo estoy en la Vega Monumental y me rodean, me dan vuelta y me elevan, son dos, y me van tapando la boca y la vista, pero hay gente, entonces un secuestro es.... lo que tengo ahí son 5, 7, 10, películas, tenía un arma, pero las armas que me apuntaban deben haber sido unas $20 .$. o sea todo es grosero, es como un paredón" 69 . A su vez, este testimonio confirma el extremo nivel de violencia con el que fue tratado desde el inicio de su detención.

Por otra parte, María Arroyo Soto también relata los hechos de violencia sufridos al momento de ser detenida: "A mi esposo lo tiran al suelo violentamente, lo encapuchan y esposan agentes de la CNI, de ahí es pasado a carabineros llevándolo al furgón de su institución. Agentes del CNI realizan el allanamiento dando vuelta todo lo que encontraban a mano bajo mi presencia. Luego de aproximadamente 45 minutos, 2 miembros del CNI me llevan en un auto hacia su cuartel [...]"70.

$\mathrm{Al}$ respecto, el grado de maltrato utilizado en este recinto, ha sido consignado también por la Comisión Valech, que describe que, durante el período de su funcionamiento, entre los años 1981 y 1984 , algunos de los métodos de maltrato y tortura son:

"Mientras permanecían en este recinto los prisioneros estaban con los ojos vendados, incomunicados, privados de alimento y sueño [...] Los testimonios de los detenidos denunciaron que sufrieron golpes, aplicación de electricidad, el teléfono, colgamientos, obligación de permanecer en posiciones forzadas, pau de arara, incomunicación prolongada y amenazas." 71

En dicho contexto Patricia Zalaquett Daher ${ }^{72}$ manifiesta que:

“[...] se me trasladó a un cuartel de la CNI en Concepción. Se me introdujo en una pieza donde una mujer me hizo algunas preguntas, me golpeó fuertemente en la cara y me amenazó con 'parrillarme' en el acto. Fui llevada a una pieza dónde al parecer había otros detenidos. Yo siempre permanecía vendada, pero escuché sus voces cuando respondían preguntas de algunos agentes de la CNI. Luego de una hora más o menos me hicieron subir escaleras y fui situada de pie, esposada y vendada junto a otros detenidos $[\ldots]]^{\prime 73}$.

Un aspecto que también puede ser calificado de violencia era la cantidad de personal que Investigaciones utilizaba para realizar las detenciones y que mantenía como "personal" destinado a torturar y a apoyar las labores domésticas en el Cuartel. Otro detenido señala que: "En Bahamondes deben haber operado unas 30 o 40 personas como mínimo, hay conductores, gente de la cocina, choferes... El torturador y los interrogadores se cansan y tienen una sala, donde toman café y tienen una tele y se acuestan a dormir. Por ejemplo, una cosa bien especial es que llegan mujeres y no hay ninguna

${ }^{69}$ Información comunicada en entrevista personal el 25 de marzo de 2018. Nombre confidencial.

70 Testimonio de María Isolina Arroyo Soto. Archivo del Arzobispado de Concepción, 1984.

${ }^{71}$ Informe de la Comisión Nacional sobre Prisión Política y Tortura, 2004, p. 375.

72 Patricia Zalaquett Daher, conyugue de Nelson Herrera -asesinado en la Vega Monumental-. Fue detenida el día 23 de agosto durante el despliegue de la operación Alfa Carbón, a las 16:30 hrs en su domicilio ubicado en el pasaje Río Pudeto 2756, Villa el Recodo, camino Concepción-Santa Juana, por 10 o 15 agentes de la CNI, según consta su testimonio. Tras su paso por recintos de la CNI, fue trasladada a la Cárcel Publica de Mujeres en Coronel. No obstante, en su calidad de detenida e incomunicada, no supo de la muerte de su esposo. Así lo consignaba Las últimas noticias del jueves 30 de agosto de 1984, bajo el titular "Detenida por la CNI no sabe que su esposo murió.

73 Testimonio de detención Patricia Zalaquett, archivos Arzobispado de Concepción, 1984. 
mujer presa, ninguna mujer de la CNI está presa. Llegan mujeres y yo estoy amarrado al catre [de tortura] y me manosean y me dicen "mijito ¿y qué pasaría si te violamos?" 74 . Este relato da cuenta del papel protagónico que tenían los civiles y en particular, las mujeres civiles como abusadoras sexuales, aspecto que aún no ha sido estudiado en detalle.

Este nivel de violencia, tuvo como principal objetivo, especialmente el año 1984, desbaratar completamente la estructura del MIR que, como ha sido señalado, ya había logrado constituirse en la zona sur luego de la Operación Retorno y la resistencia desbaratada de Neltume. Según se ha constatado en diversos testimonios ${ }^{75}$, la cúpula de la estructura del Movimiento era perseguida por sus diversas acciones de resistencia y también porque, en la estructura del MIR contaban con armas cuyo objetivo era atentar contra la dictadura cívico militar. Sin embargo, los recursos en armamentos que poseía el grupo fueron sobrestimados por los Servicios de Inteligencia de la época. Al respecto, en un tono anecdótico Ignacio Vidaurrázaga, detenido en el Cuartel, comenta que durante su detención se tuvo la sospecha que él tendría explosivos en los cierres de su chaqueta: "adentro, la actitud cuando vamos en el auto, es que me pegan, me tapan la boca... yo tengo una chaqueta verde que tenía cierre y los tipos cuando van encima mío en la parte trasera del auto, dicen: cuidado, cuidado porque este huevón puede tener explosivos en los cierres. En los cierres ellos imaginaban que yo podía volarme con ellos y eso no se había visto nunca en Chile, los tipos habían visto muchas películas, además yo tenía un arma especial con doble cargador, etc. Y de ahí es el camino a la muerte." 76

Así, en el despliegue de la operación destinada a neutralizar al MIR, se hicieron constantes los allanamientos -desde las $11 \mathrm{hrs}$ hasta las $18 \mathrm{hrs}$ aproximadamente- a domicilios de quienes posteriormente fueron detenidos y trasladados al Cuartel Bahamondes.

En calle Nápoles, Hualpencillo, a las 13:30 hrs fue detenida María Isolina Arroyo Soto, conyugue de Miguel Barriga Gutiérrez, ambos trasladados detenidos al cuartel ${ }^{77}$. En los casi 8 días que estuvo recluida permaneció vendada y esposada ${ }^{78}$. Por otra parte, Alejando Bernstein fue detenido en Alonso Ovalle $n^{\circ} 29$, Lomas de San Andrés, entre las 17 y 18 hrs. Se declaró ayudista de la resistencia en redacciones de documentos políticos, siendo su jefe directo, Nelson Herrera ${ }^{79}$. Mónica del Pilar Martínez Barra, detenida junto a su madre, Lidia Barra, y otra menor, de quien se desconoce el nombre, fueron detenidas en Pedro de Oña 135, Lorenzo Arenas ${ }^{80}$.

No obstante, en la actualidad el Cuartel aún no tiene suficientes elementos que permitan su identificación, especialmente luego del cambio de numeración, de Pedro de Valdivia número 710 a 701 y

\footnotetext{
${ }^{74}$ Información comunicada en entrevista personal el 25 de marzo de 2018. Nombre confidencial

75 Un comunicado oficial emitido el día 24 de agosto de 1984 por la Intendencia de la octava región, indicaba que: "en el allanamiento del inmueble ubicado en el pasaje Doce $N^{\circ} 3346$ de la población Armando Alarcón del Canto" encontraron un vasto armamento que constaba de "Una subametralladora calibre $9 \mathrm{~mm}$, una pistola calibre $9 \mathrm{~mm}$, explosivos de diferentes tipos, [...]” entre otros. El documento continúa: en el allanamiento al inmueble ubicado en calle Pedro de Oña No 135 en Concepción. "Al registrarse el domicilio se encontraron seis cartuchos de amón gelatina y cuatro metros de cordón detonante, además de documentación de carácter subversivo”. El documento prosigue, señalando que en cada allanamiento se encontró un número significativo de armas de gran variedad, justificando de cierta forma, el accionar violento -relatado por los testigos- de los agentes de la CNI. Alejandro Bernstein, después de su violenta detención y allanamiento manifestó que: "Se escuchaban voces que decían 'aquí no hay nada', lo que motivaba preguntas hacia mí, tales como ¿dónde escondes las armas?, ¿cómo se llega al entre techo?”. Testimonio extraído del Archivo del Arzobispado de Concepción.

76Relato de la detención. Entrevista personal con la autora.

${ }^{77}$ Arroyo y Barriga fueron acusados de participar en el ataque a un funcionario de la CNI en Temuco y en tareas de propagandas que el MIR realizaba en la zona sur, utilizando identidades falsas. Por otra parte, tras su allanamiento, se les acusa además de habérseles encontrado explosivos, municiones, una subametralladora, un revólver y abundante documentación subversiva. Diario El Mercurio y El Sur del día viernes 31 de agosto de 1984.

78 Testimonio de detención, María Isolina Arroyo, archivo Arzobispado de Concepción, 1984.

79 Testimonio de Alejandro Bernstein, archivos Arzobispado de Concepción, 1984.

${ }^{80}$ Ficha de detenidos, archivo del Arzobispado de Concepción, 1984.
} 
menos aún, después de la posterior demolición de la casona donde este se ubicaba ${ }^{81}$ y el emplazamiento de un edificio residencial en ese lugar. Esto dificulta el reconocimiento del lugar como sitio de memoria e incide en la posibilidad de realizar prácticas de memoria.

En el fallo que realizara el juez Carlos Aldana en abril de 2018, de conocimiento público, se especifica la relevancia de este Cuartel, no solo como recinto de detención y tortura, sino también como un centro de operaciones que actuaba en directa coordinación con oficinas a cargo de la CNI de Santiago, desde donde recibían órdenes directas. En concreto, el fallo, que se pronunció después de una década de investigación, solo condena a 17 agentes de la CNI, absolviendo algunos acusados y sin condena para ningún civil, lo que evidencia que la mayoría de los victimarios siguen aún en la impunidad.

\section{Conclusiones}

El objetivo central de este artículo atiende a visibilizar la violencia política durante la dictadura cívico militar, por parte del Estado en Chile en general y en Concepción en particular. Luego de lo ya señalado, es posible constatar que las acciones represivas en la ciudad desbarataron cualquier posibilidad de resistencia, logrando exterminar incluso a los movimientos de oposición durante la década de los 80 . Un ejemplo de ello, es el fracaso de la Operación Retorno.

En Concepción, durante la década de los 80, especialmente el año 1984, se implementaron acciones de extrema violencia política, como la instalación del Cuartel Bahamondes en Concepción, cuyo objetivo fue aniquilar y exterminar a la cúpula e integrantes del "Movimiento de Izquierda Revolucionario" (MIR). Ha sido demostrado, como consta en las fuentes primarias y secundarias citadas, que los partidarios de este Movimiento desarrollaron acciones de lucha con un escaso conocimiento de las operaciones de Inteligencia realizadas en su contra, con muy pocos recursos y con el costo de perder la mayoría, si no todos, los líderes que comandaban el Movimiento y por lo tanto de debilitar la organización.

Por otra parte, tal como ha sido señalado, este Cuartel ha sido invisibilizado en forma activa, lo que pone de manifiesto la necesidad de repensar los efectos sociales de estos "lugares desaparecidos" como consecuencia del olvido, en términos de la transmisión de la memoria de lo acontecido allí. En este sentido, los acontecimientos vinculados con la represión, tortura y desaparición, ponen de relieve diversos aspectos. En un sentido general, se destaca la importancia de los archivos y narrativas testimoniales como única huella que mantiene la existencia simbólica del lugar. Además, acentúan la necesidad de justicia para quienes estuvieron detenidos allí y confrontan con la situación de impunidad, especialmente de los civiles, y que se perpetúa a más de tres décadas. Finalmente, permiten interrogar por un asunto ético, a saber, la falta de reconocimiento, las deudas transgeneracionales ante el sufrimiento y especialmente, el compromiso social y político que la sociedad tiene ante la violación de los derechos humanos.

\section{Bibliografía}

\section{Libros y artículos}

- Acuña, María G., Archivosy memoria de la represión en América Latina (1973-1990), Santiago de Chile, LOM ediciones, 2016.

- Arancibia, Eduardo, Las milicias de la resistencia popular: El MIR y la lucha social armada en dictadura 1979-1984, Concepción, Ediciones Escaparate, 2015.

- Arendt, Hannah, Sobre la violencia, Madrid, Alianza Editorial, 2005.

\footnotetext{
81 Los años exactos en que se realizaron el cambio de número y la posterior demolición, no han podido ser definidos con exactitud, pues estos mismos hechos han dificultado la búsqueda de los antecedentes de la historia de la propiedad.
} 
- Aróstegui, Julio, "Violencia, sociedad y política". Ayer, N¹3, 1994.

- Barreto, Idaly y Borja, Henry, "Violencia política: algunas consideraciones desde la psicología social”, Revista Diversitas, N¹, Vol. 3, 2007.

- Bello, Marcela, Entrevista con Florencia Levín, 16 de marzo 2015. Recuperado de http://argentinainvestiga.edu.ar/

- Campero, Guillermo, Entre la sobrevivencia y la acción política: Las organizaciones de pobladores en Santiago, Santiago de Chile, Ediciones ILET, 1987.

- Carrasco, Bambina y Fuentes, Jennifert, Intervención Tanatologica del Estado en Lorenzo Arenas. La Operación Alfa Carbón y sus consecuencias, Tesis para optar al título profesional de Trabajador (a) Social, Universidad del Bío-Bío, Concepción, 2016.

- Cortina, Adela, "Ética y violencia política”, Revista Sistema, 132-133, 1996.

- Domenach, Jean, et al. (eds.), La violencia y sus causas, París, Editorial UNESCO, 1981.

- Franco, Marina y Levín, Florencia (eds.), Historia reciente. Perspectiva y desafíos para un campo en construcción, Buenos Aires, Paidós, 2007.

- Garcés, Mario y de la Maza, Gonzalo, La explosión de las mayorías. Protesta Nacional 1983-1984, Santiago de Chile, ECO, 1985.

- Garcés, Mario; Milos, Pedro y Olguín, Myriam (eds.), Memorias para un nuevo siglo. Chile, miradas a la segunda mitad del siglo XX, Santiago de Chile, LOM ediciones, 2000.

- Garcés, Mario y Leiva, Sebastián, El golpe en la Legua: Los caminos de la historia y la memoria, Santiago de Chile, LOM Ediciones, 2005.

- Goicovic, Igor, Movimiento de Irquierda Revolucionaria, Concepción, Ediciones Escaparate, 2012.

- Goicovic, Igor, Trabajadores al poder. El Movimiento de Izquierda Revolucionaria (MIR) y el proyecto revolucionario en Chile (1965-1994), Concepción, Ediciones Escaparate, 2016.

- Guillaudat, Patrick y Mouterde, Pierre, Los movimientos sociales en Chile: 1973-1993, Santiago de Chile, LOM Ediciones, 1998.

- Hernández, Hilario, "El gran Concepción: Desarrollo histórico y estructura urbana. Primera parte. Génesis y evolución: De las fundaciones militares a la conurbación industrial", Revista de Informaciones Geográficas, No 30, 2001.

- Hernández, Sergio y Medina, Eduardo, La experiencia de la Fuerza Central del MIR 1979-1983: Vivencias y reflexiones de dos sobrevivientes, Concepción, Ediciones Escaparate, 2017.

- Iglesias, Mónica, Rompiendo el cerco. El movimiento de pobladores contra la dictadura, Santiago de Chile, Ediciones Radio Universidad de Chile, 2011.

- Matus, Alejandra, "La victoria de la CNI sobre el MIR", extraído de http://www.casosvicaria.cl/temporada-uno/la-victoria-de-la-cni-sobre-el-mir/

- Monsálvez, Danny, "Violencia y represión en un dispositivo local: Concepción, 11 de septiembre de 1973", Revista de Historia y Geografia, N²6, 2012.

- Palma, José, El MIR y su opción por la Guerra Popular: Estrategia político-militar y experiencia militante 1982-1990, Concepción, Editorial Escaparate, 2012.

- Pérez, Cristian, "Historia del MIR. Si quieren guerra, guerra tendrán”, Estudios Públicos, $\mathrm{N}^{\circ} 91$, 2013.

- Pinto, Julio; Álvarez, Rolando y Valdivia, Verónica, Su revolución contra nuestra revolución. Vol. II. La pugna marxista-gremialista en los ochenta, Santiago de Chile, LOM Ediciones, 2008.

- Pozzi, Pablo y Pérez, Claudio (Eds.), Por el camino del Che. Las guerrillas latinoamericanas, 1959-1990, Buenos Aires, Imago Mundi. 
- Salazar, Manuel, Las letras del horror, Tomo II: La CNI, Santiago de Chile, LOM Ediciones, 2012.

- Sandoval, Carlos, Movimiento de Izquierda Revolucionaria, 1980-1986, Tomo IV, Santiago de Chile, Editorial Quimantú, 2014.

- Silva, Robinson, Resistentes y clandestinos: La violencia politica del MIR en la dictadura profunda 19781982, Concepción, Editorial Escaparate, 2011.

- Talancón Escobedo, Jaime, "La violencia política", Revista de la Facultad de Derecho de México, N²51, Vol. 59, 2009.

- Tricot, Tito, "Reflexiones sobre la violencia política", Araucaria de Chile, N³4, Madrid, 1986.

- Turk, Austin, "La violencia política desde una perspectiva criminológica", Revista Sistema, $\mathrm{N}^{\circ}$ 132-133, 1996.

- Valdés, Mario, "El golpe de Estado del 11 de septiembre de 1973 en Concepción (Chile). Las voces de los testigos", Cuadernos de bistoria, N³7, 2012.

- Vega, María Eliana, No bay dolor inútil. La iglesia de Concepción y su defensa de los derechos humanos en la región del Biobio entre 1973 y 1991, Concepción, Chile, 1999.

- Weinstein, José, Los jóvenes pobladores en las protestas nacionales (1983-1984), Santiago de Chile, CIDE, 1989.

- Whelan, James, Desde las cenizas. Vida, muerte y transfiguración de la democracia en Chile 1833-1988, Santiago de Chile, Editorial Zig-Zag, 1993.

\section{Diarios, periódicos y revistas}

- El Sur [Concepción] 1984.

- Las últimas noticias [Santiago] 1984

- El Mercurio [Santiago] 1984

- Cance [Santiago] 1984

- Apsi [Santiago] 1984

- Solidaridad [Santiago] 1984

\section{Fuentes}

- Archivo del Arzobispado de Concepción, 1984.

- Informe Comisión Nacional sobre Prisión Política y Tortura, Santiago, 2004.

- Informe de la Comisión Nacional de Verdad y Reconciliación, 1996.

\section{Entrevista}

- Ignacio Vidaurrazaga, domingo 25 de marzo de 2018

\section{Sitios web}

- www.memoriaviva.cl

- www.ciperchile.cl 